\title{
PENGEFEKTIFAN PENGGUNAAN RUANG PENYIMPANAN SPARE PART MEKANIK PT.INDOCEMENT PLANT 3/4
}

\author{
Fahmi Husaeni $^{1}$, M Anwar Septiana ${ }^{2}$, Cahya Laksana ${ }^{3}$ \\ Program Studi Teknik Industri ${ }^{1,2,3}$ \\ Fakultas Teknik Universitas Widyatama \\ Jl. Cikutra No. 204 A Bandung \\ fhusaeni37@gmail.com ${ }^{1}$
}

\begin{abstract}
Abstrak
PT. Indocement merupakan perusahaan yang memproduksi semen yang sudah berdiri sejak tahun 1985, dan sudah memiliki 13 pabrik yang berlokasi di 3 daerah, yaitu Bogor, Palimanan dan Tarjun. Pada sebuah pabrik terdapat beberapa unit kerja diantaranya bagian produksi, elektrik, dan mekanik. Pada bagian mekanik terdapat gudang penyimpanan Spare part, yang digunakan untuk menyimpan Spare part untuk mesin-mesin produksi. Gudang sekarang yang digunakan luasnya tidak telalu besar hanya berukuran $5 \mathrm{~m} \times 7 \mathrm{~m}$. Jumlah Spare part yang disimpan sangat banyak dengan berbagai ukuran Spare part mulai dari yang kecil hingga ukuran Spare part yang besar, penyimpanan terkesan tidak berdasarkan jenis dan ukuran sehingga banyak Spare part yang berukuran kecil tertumpuk dan tidak terlihat karena tertutup oleh Spare part yang ukuran lebih besar, sehingga sering kali dilakukan pemesanan ulang untuk Spare part yang sebenarnya masih tersedia di gudang. Pengeluaran biaya untuk pembelian Spare part menjadi lebih besar. Metodologi yang kami gunakan adalah metodologi kualitatif,. Menggunakan metode Class-based storage atau dengan menempatkan material berdasarkan atas kesamaan jenis maupun kesamaan ukuran. Penerapan design ulang penempatan Spare part, maka diharapkan Spare part akan lebih mudah ditemukan dan Spare part dapat digunakan secara maksimal, sehingga dapat menekan biaya untuk pembelian Spare part. Manfaat lain adalah akan terlihat lebih rapi dan mudah untuk membersihkan area gudang sewaktuwaktu.
\end{abstract}

\begin{abstract}
PT. Indocement is a cement producing company that has been established since 1985, and already has 13 factories located in 3 areas, namely Bogor, Palimanan and Tarjun. In a factory there are several work units including production, electrical and mechanical. In the mechanical part there is a spare part storage warehouse, which is used to store spare parts for production machines. The warehouse currently used is not too large in size only $10 \mathrm{~m} \times 5 \mathrm{~m}$. The number of spare parts that are stored very much with various sizes of spare parts ranging from small to large size spare parts, storage does not seem based on the type and size so that many small spare parts are piled up and not visible because they are covered by larger sized spare parts, so it is often re-ordered for spare parts that are actually still available in the warehouse. Spending costs for purchasing spare parts becomes greater. The methodology we use is a qualitative methodology. Using the Class-based storage method or by placing material based on the same type or similar size. Implementation of the redesign of the placement of spare parts, it is expected that spare parts will be easier to find and spare parts can be used optimally, so as to reduce the cost of purchasing spare parts. Another benefit is that it will look neater and easier to clean the warehouse area at any time.
\end{abstract}

Keywords:

Spare part, warehouse, cost, storage

Kata Kunci:

Spare part, Gudang, biaya, Penyimpanan

Fahmi Husaeni, M Anwar Septiana, Cahya Laksana 


\section{Pendahuluan}

PT. Indocement merupakan perusahaan yang memproduksi semen yang sudah berdiri sejak tahun 1985, dan sudah memiliki 13 pabrik yang berlokasi di 3 daerah, yaitu Bogor, Palimanan dan Tarjun. Dalam satu pabrik yang beroperasi terdapat beberapa department antara lain Production Departement, Electrical Departement, dan Mechanical Departement. Penelitian ini mengambil masalah yang timbul di Mechanical Departement dimana di gudang yang menjadi tempat penyimpanan Spare part, kondisi nya tidak sesuai dengan kaidah-kaidah tata letak pergudangan. Spare part ditempatkan secara acak dan tidak tersusun secara rapi, sehingga banyak Spare part yang saling menumpuk yang berakibat pada kerusakan beberapa Spare part sebelum digunakan.

Tata letak pergudangan sendiri memiliki petunjuk-petunjuk dalam mengelola dalam menyimpan barang-barang yang ada di dalam gudang dengan memaksimalkan fasilitas yang sudah tersedia di dalam gudang. Penerapan dengan memanfaatkan fasilitas yang minimum tetap dapat dimaksimalkan agar lebih memudahkan Spare part yang masuk maupun yang keluar.

Pendekatan yang digunakan adalah pendekatan kualitatif dengan menggunakan metode Class-based storage, untuk mengatur penyimpanan Spare part di dalam gudang berdasarkan jenis maupun ukuran yang sama. Diharapkan dengan penyimpanan sesuai jenis dan ukuran maka akan lebih mudah untuk mencari Spare part, menghindari saling menumpuknya barang-barang, menghindari kerusakan Spare part dari kerusakan sebelum digunakan, dan untuk menekan biaya pembelian Spare part yang rusak ataupun hilang sebelum digunakan.

Batasan-batasan pada penelitian ini:

1. Tidak mengubah dimensi bangunan gudang yang sudah tersedia.

2. Tidak mengurangi atau menambahkan fasilitas yang ada di dalam gudang.

3. Tidak mengubah sistem produksi.

4. Tidak mengubah sistem penerimaan maupun pengeluaran Spare part yang akan digunakan.

\section{KAJIAN LITERATUR}

\section{A. Gudang}

a. Pengertian gudang

Gudang merupakan tempat penyimpanan material yang diperlukan untuk proses produksi, material tersebut akan terus disimpan hingga siap diproses sesuai dengan jadwal produksi atau order konsumen. Aktivitas yang umumnya dilakukan berkaitan dengan penyimpanan material dalam gudang, adalah Receiving, Prepacking, Put-away, Storage, Order picking, Packaging, Sortation, accumulation, Packing and Shipping.

b. Fungsi pokok dari gudang adalah sebagai berikut:

1. Receiving, meliputi aktivitas menerima semua produk serta menyediakan jaminan bahwa kualitas dan kuantitas produk sesuai dengan yang dibeli.

2. Prepackaging, meliputi aktivitas yang dilakukan jika produk yang diterima dalam partai besar dari supplier dan sesudah itu dibungkus satu demi satu atau dikombinasikan dengan produk yang lain.

3. Putaway, meliputi tindakan menyimpan produk dalam tempat penyimpanan.

4. Storage, meliputi aktivitas penahanan secara fisik produk sebelum diproses.

5. Order picking merupakan proses memindahkan item-item dari tempat penyimpanan untuk diproses sesuai dengan permintaan.

6. Packaging and/or pricing, merupakan langkah pilihan yang dapat dilakukan setelah proses pengambilan.

7. Sortation, melakukan pengklasifikasian kedalam permintaan - permintaan individu.

8. Untizing and shipping, meliputi aktivitas pengecekan, pengemasan, menyiapkan dokumen pengiriman, penimbangan pengiriman, mengumpulkan order dan pemuatan.

9. Cross-docking, merupakan aktivitas menerima kemudian langsung dikirim.

Fahmi Husaeni, M Anwar Septiana, Cahya Laksana 

10. Replenishing, merupakan aktivitas pengambilan dari tempat penyimpanan cadangan.

c. Jenis-jenis gudang adalah sebagai berikut:

1. Raw material and component warehouses yaitu tempat untuk menyimpan bahan baku utama dan bahan baku penunjang.

2. Work in-process warehouses yaitu tempat untuk menyimpan produk yang masih belum selesai diproses.

3. Finished goods warehouses yaitu tempat untuk menyimpan produk jadi.

4. Distribution warehouses and distribution centers yaitu tempat penyimpanan yang menghimpun berbagai macam produk darisatu perusahaan maupun banyak perusahaan, untuk memenuhi permintaan konsumen.

5. Fulfillment warehouses and fulfillment centers yaitu tempat yang menerima, menyimpan dan mengirim order kecil dari konsumen individu.

6. Local warehouses yaitu gudang yang memiliki peran untuk memperpendek jalur transportasi agar mampu mengatasi respon cepat dari permintaan konsumen.

7. Value-added service warehouses yaitu gudang yang hanya memiliki fasilitas seperti packaging, pemberian label, pemberian tanda, pemberian harga dan proses lainnya.

B. Tata letak

a. Pengertian Tata letak

Perancangan tata letak adalah pengaturan konfigurasi stasiun kerja produksi yang disusun berdasarkan interaksi antar departemen yang memenuhi kriteria-kriteria tertentu sehingga interaksi tersebut optimal dalam proses transformasi material dari bahan mentah menjadi produk jadi.

Perencanaan tata letak merupakan salah satu tahap perencanaan fasilitas yang bertujuan untuk mengembangkan suatu sistem produksi yang efektif dan efisien sehingga tercapai suatu proses produksi dengan biaya yang paling ekonomis.

b. Tata letak gudang
Perancangan tata letak gudang terdapat beberapa prinsip yang umum dijadikan sebagai acuan, yaitu: Popularity, Similarity, Size, Characteristics dan Space utilization. Beberapa karakteristik komponen yang penting yaitu: Perishable materials (komponen yang mudah rusak), Cddly shaped and crushable items (komponen bentuk khusus dan mudah rusak), Hazarduous materials (komponen berbahaya), Security items (komponen dengan pengamanan khusus) dan compability (kecocokan/kesesuaian).

Tujuan perencanaan Tata Letak Gudang Bahan Baku/jadi:

1. Utilisasi luas lantai luas

2. Menyediakan pemindahan bahan yang efisien

3. Meminimalisasi biaya penyimpanan

4. Mencapai fleksibilitas maksimum

5. Menyediakan house keeping yang baik

c. Faktor-faktor yang harus dipertimbangkan dalam mengembangkan tata letak adalah:

1. Conservation of space

Pengaturan fasilitas sehingga terdapat fleksibilitas dan kemampuan memenuhi permintaan yang besar.

2. Limitations of space

Pengaturan batasan suatu bahan dapat disimpan dalam suatu tempat seperti batas banyak tumpukan agar tidak merusak bahan yang ada.

3. Accessibility

Merupakan pembuatan ruang gerak agar bahan dapat dipindahkan dengan mudah menggunakan material handling yang tersedia. Ilustrasi tentang pertimbangan pengaksesan barang yang disimpan disajikan.

d. Jenis-jenis kebijakan penempatan barang

1. Random storage

Penempatan barang berdasarkan tempat yang paling dekat dengan lokasi input barang, implikasi kebijakan ini adalah waktu pencarian barang lebih lama. Random storage memerlukan sistem informasi yang baik, umumnya cara ini dilakukan pada sistem AS/RS (Automated Storage/Retrievel System).

2. Fixed storage atau dedicated storage Aplikasi kebijakan yang menempatkan satu jenis bahan atau material di tempat yang khusus hanya untuk bahan atau material

Fahmi Husaeni, M Anwar Septiana, Cahya Laksana 
tersebut. Kebijakan ini akan mengurangi waktu dalam pencarian barang, namun ruang yang dibutuhkan menjadi kurang efisien karena ruang kosong untuk satu bahan atau material tidak diperbolehkan untuk ditempati bahan atau material lainnya.

3. Class-based storage

Yaitu penempatan bahan atau material berdasarkan atas kesamaan suatu jenis bahan atau material kedalam suatu kelompok. Kelompok ini nantinya akan ditempatkan pada suatu lokasi khusus pada gudang. Kesamaan bahan atau material pada suatu kelompok, bisa dalam bentuk kesamaan jenis item atau kesamaan pada suatu daftar pemesanan konsumen.

4. Shared storage

Penempatan beberapa bahan atau material dalam satu area yang dikhususkan untuk bahan atau material tersebut. Kebijakan ini mengurangi jumlah kebutuhan luas gudang dan mampu peningkatkan utilisasi area penempatan persediaan.

\section{Analisis dan Perancangan}

Dalam penelitian ini membutuhka data mengenai gambaran tata letak gudang spare part yang ada di PT. INDOCEMENT, seperti dimensi gudang, jenis lemari atau rak yang digunakan, fasilitas yang tersedia, jenis material yang disimpan, karakteristik material yang disimpan, jenis material handling yang digunakan. Data-data yang diperlukan diatas sangat mendukung untuk kelancaran penelitian ini, dan data didapatkan dengan cara langsung melihat ke lokasi gudang yang ada di area PT. INDOCEMENT. Data tentang dimensi gudang diperlukan unutuk mengetahui seberapa luas area gudang yang dapat dimanfaatkan untuk memaksimalkan penggunaan ruang penyimpanan spare part, lalu data data tentang lemari yang digunakan diperluksn untuk mengetahui tentang berapa besar spare part yang bisa dimuat. Lalu data tentang fasilitas yang tersedia adalah untuk memaksimalkan fasilitas yang ada dengan harapan tidak perlu menambah ada nya fasilitas tambahan, lalu data tentang karakteristik material yang disimpan diperukan untuk mengeompokan material berdasarkan jenis ukuran, sifat material, maupun bahan dasar dari pembuatan material tersebut. Sedangkan data tentang material handling diperlukan untuk mengetahui akses yang bisa digunakan untuk pergerakan peralatan material handling agar bisa digunakan secara maksimal. Penelitian ini diakukan dalam beberapa tahap, yaitu tahap pendahuluan, tahap studi tentang tata letak gudang, tahap pengumpulan dan pengolahan data, dan terakhir tahap kesimpulan dan saran. Tahap pendahuluan merupakan tahap pengamatan awal mengenai tata letak gudang, dimensi gudang, karakterikstik material yang disimpan, fasilitas yang tersedia, peralatan material handling yang digunakan. Lalu tahap studi tentang tata letak gudang diperukan untuk mengetahui tentang kaidah-kaidah tata letak pergudangan agar penelitian ini mendapat hasil yang maksiamal. Lalu tahap pengumpulan dan pengoahan data, pada tahap ini data dikumpulakan dan diolah agar mendapat hasil dan kesimpulan baru mengenai tata letak gudang yang akan digunakan. Tahap terakhir merupakan kesimpulan dan saran, dimana pada tahap ini didapat lay out gudang yang baru dan dapat memaksimalkan fasilitas yang ada dan diharapkan dapat menambah kapasitas gudang.

Pengumpulan data dilakukan dengan meninjau langsung lokasi pergudangan yang berada di area PT. INDOCEMENT beberapa data yang berhasil di dapatkan adalah sebagai berikut :

1. Dimensi gudang $5 \mathrm{~m} \times 7 \mathrm{~m}$ dengan satu akes pintu keluar masuk dengan ukuran $2 \mathrm{~m}$ x 1,5m.

2. 2 rak ukuran $2 \mathrm{~m} \times 1 \mathrm{~m} \times 1 \mathrm{~m}, 2$ lemari berukuran $2,5 \mathrm{~m} \times 1 \mathrm{~m} \times 2 \mathrm{~m}, 2$ lemari besi 2 pintu berukuran $1, \mathrm{~m} \times 1 \mathrm{~m} \times 2 \mathrm{~m}$

3. Troli dorong berukuran $60 \mathrm{~cm} \times 30 \mathrm{~cm}$ untuk membawa sapre part dengan ukuran yang tidak terlalu besar.

4. Terdapat 1 buah meja kerja dan kursi untuk operator mendata barang yang masuk dan barang keluar.

5. Terdapat 1 buah lemari kecil untuk menyimpan pembukuan mengenai jenis-jenis sapre part berdasarkan jenis dan code number nya.

\section{Proses masuk dan keluar spare part}

Spare part yang masuk dan keluar tidak selalu sama setiap harinya, tergantung bagaimana kebutuhan dari proses maintenance yang ada di lapangan. Sehingga proses pemesanan kembali spare part yang sudah berkurang pun tidak selalu terjadwal pasti, begitupun lead time pada saat pemesanan spare part tidak bisa diketahui secara pasti. Salah satu masalah

Fahmi Husaeni, M Anwar Septiana, Cahya Laksana 
yang muncul adalah ketika barang dating dalam jumlah besar, karena kekurangan tenaga operator di gudang, maka sebagian spare part diletakan sembarang tidak pada tempat nya, sehingga banyak spare part yang tertumpuk ataupun rusak sebelum digunakan sehingga mengakibatkan kerugian secara finansia dan dapat mengganggu jadwal maintenancedan terganggu pula jadwa produksi.

\section{Karakteristik Spare part}

Beragam nya jenis peralatan dan mesin yang digunakan dalam proses produksi pembuatan semen, sehingga mempengaruhi pula banyaknya terhadap banyak nya jenis spare part yang dibutuhkan untuk mesin produksi. Beberapa spare part tersebut dibagi menjadi dua kategori yaitu spare part fast moving dan slow moving. Ada juga spare part penunjang yang penggunannya tidak banyak digunakan, cenderug digunakan hanya ketika saat-saat tertentu saja, contoh nya ketika mesin produksi mencapai waktunya untuk overhaul atau servis besar. berikut beberapa spare part yang disimpan didalam gudang:

Tabel 1 Klasifikasi Spare Part

\begin{tabular}{cl}
\hline \hline Nama spare part & Kategori \\
\hline $\begin{array}{c}\text { Baut dan mur } \\
\text { berbagai ukuran }\end{array}$ & Fast moving \\
\hline \hline Bearing & Slow moving \\
\hline \hline Housing bearing & Slow moving \\
\hline \hline Seal bearing & Slow moving \\
\hline \hline Silicone & Fast moving \\
\hline \hline Mata gerinda & Slow moving \\
\hline \hline Amplas & Fast moving \\
\hline \hline
\end{tabular}

Selama ini penempatan barang tersebut tidak sesuai dengan tempat nya atau terkesan asal dalam penyimpanan nya. Contoh nya baut dan mur yang disimpan di rak dengan kotak kayu namun tidak dipisahkan berdasarkan ukurannya dan juga antara mur danbaut yang bersatu dalam satu kotak kayu tanpa diberi pembatas. Hal tersebut menghambat ketika meakukan pencarian baut dan mur dengan ukuran tertentu. Contoh lain adalah pelumas atau grease yang disimpan sembaranagan tanpa memeakai tatakan agar sisa2 dari grease tersebut tidak berceceran di lantai.

\section{Tata letak gudang}

Gudang yang saat ini sudah didesain sejak dulu sudah sesuai dan sangat sedikit yang bisa dilakukan untuk merubah posisi lemari atau rak, karena keterbatasan dimensi gudang yang tidak terlalu besar ditambah hanya ada satu akses keluar masuk melalui pintu yang sama. Masalah yang timbul adalah penempatan spare part yang dilakukan secara tidak teratur, menyulitkan operator untuk mencari barang yang sedang diperlukan. Akibatnya waktu pengambilan barang menjadi lebih lama karena barang yang dicari tidak diketahui lokasi persis nya ataupun mungkin tertumpuk dengan barang-barang lain. Tidak terdapat nya tanda atau petunjuk mengenai lokasi barang semakin membuat proses pengambilan barang di gudang menjadi semakin lama. Hal tersebut kadang menghambat proses maintenance maupun proses produksi.

\section{Tata letak gudang usulan}

Tata letak gudang yang di usulkan adalah dengan menata kembali peyimpanan spare part yang terdapat digudang dengan menggunakan metode class based storage. Dimana penyipanan dilakukan berdasarkan kesamaan jenis barang agar mudah ditemukan dan tidak bercampur dengan barang lainnya. Tidak dilakukan nya desain ulang gudang karena keterbatasan tempat yang tidak memungkinkan. Usulan yang dilakukan hanya menempatkan spare part berdasarkan kesamaan jenis nya saja. Dengan begitu akan memudahkan dalam pencarian spare part dan meminimalisir barang yang rusak karena tertumpuk dengan barang lainnya. Tempat operator melakukan pendataan barang-barang yang masuk ke gudang tidak dilakukan perubahan karena posisi yang sudah baik yaitu dekat dengan akses pintu keluar masuk, sehingga bisa terpantau aliran barang yang masuk atau pun keluar. Akses antar lemari pun masih tetaap sama yaitu selebar $1 \mathrm{~m}$, karena di dalam gudang tidak menggunakan peralatan handclift yang memiliki ukuran besar, namun hanya menggunakan troli dorong sebesar $60 \mathrm{~cm} \times 30 \mathrm{~cm}$.

Fahmi Husaeni, M Anwar Septiana, Cahya Laksana 


\section{Hasil Analisis}

Penyimpanan barang-barang di dalam gudang memiliki kaidah-kaidah atau aturan yang baku agar dalam pelaksanaan nya dapat memaksimalkan ruang yang tersedia. Dalam kasus ini masalah yang timbul adalah tidak teraturnya penyimpanan barang-barang spare part. Penyimpanan tidak teratur atau diletakan secarasembarangan tidak berdasarkan kesamaan jenis maupun kesamaan kandungan bahan dasar nya.

Usulan yang diberikan adalah penataan berdasarkan kesamaan jenis maupun kesamaan kandungan bahan dasar nya atau class based storage. Metode ini dipilih karena sesuai dengan kondisi sebenarnya yang hanya memiliki ukuran ruang yang tidak terlalu besar dan tidak mungkin juga untuk melakukan renovasi atau menata ulang gudang yang sudah ada. Dibalik itu keuntungan yang bisa didapat adalah bisa menempatkan barang-barang berdasarkan dengan frekuensi permintaan barang-barang tersebut agar ketika dibutuhkan dapat dicari dengan cepat, karena penempatannya yang berada dekat dengan pintu masuk atau keluar.

\section{KESIMPULAN}

Berdasarkan penelitian yangsudah kami lakukan, dapat ditarik kesimpulan bahwa untuk mengefektifkan penggunaan gudang dengan ukuran gudang seluas $5 \mathrm{~m}$ $\mathrm{x} 7 \mathrm{~m}$ tanpa merubah desain gudang adalah dengan menggunakan metode class based storage, dengan memiliki keuntungan seperti barang menjadi mudah dicari, barang tidak menumpuk satu sama lain, lalu barang pun lebih mudah untuk dilakukan pendataan sewaktu-waktu.

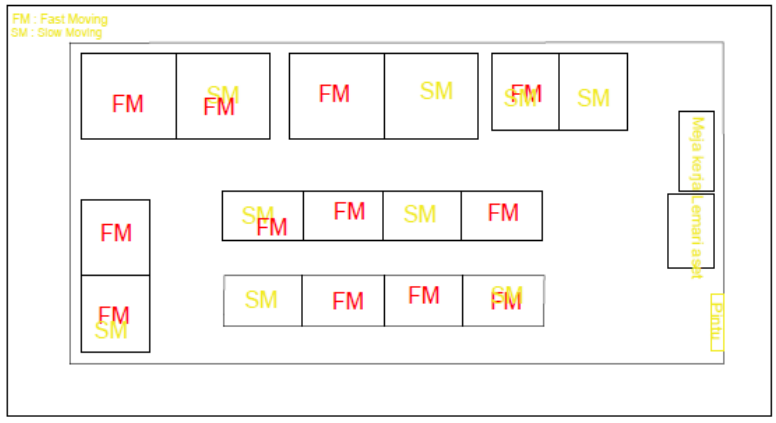

Gambar 1 Lay Out Gudang

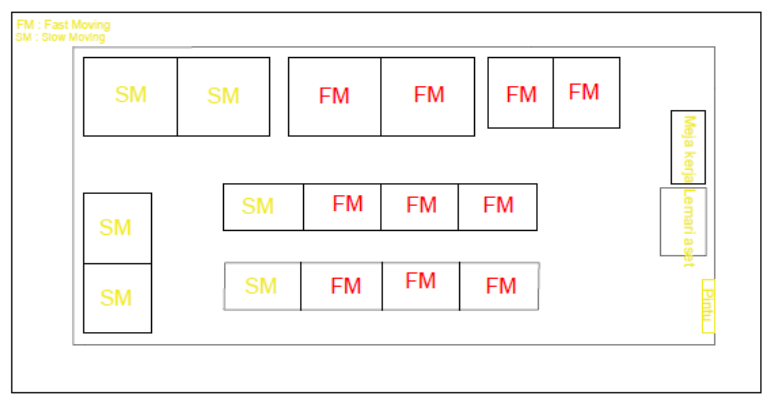

Gambar 2 Usulan Lay Out Gudang

\section{REFERENSI}

Heldy Juliana, Naniek Utami Handayani, 2016, Peningkatan Kapasitas Gudang Dengan Perancangan Layout Menggunakan Metode Class-BasedStorage,

https://ejournal.undip.ac.id/index.php/jgti/arti cle/view/11335/8850

Fahmi Husaeni, M Anwar Septiana, Cahya Laksana 